Arq. Bras. Med. Vet. Zootec., v.64, n.5, p.1161-1168, 2012

\title{
Uso do colírio de Citrus lemon em úlceras de córnea induzidas em coelhos
}

\author{
[Use of Citrus lemon eyedrops in corneal ulcers induced in rabbits] \\ C.S. Perches ${ }^{1}$, C.V.S. Brandão ${ }^{1 *}$, J.J.T. Ranzani ${ }^{1}$, C.H. Pellizon ${ }^{2}$, C. Donatti ${ }^{3}$, J.F. Fonzar ${ }^{1}$, \\ M.G. Sereno ${ }^{1}$, G.T. Angélico ${ }^{3}$, C.R. Padovani ${ }^{2}$ \\ ${ }^{1}$ Faculdade de Medicina Veterinária e Zootecnia - Botucatu, SP \\ ${ }^{2}$ Instituto de Biociências - Universidade Estadual Paulista - Botucatu, SP \\ ${ }^{3}$ Médica veterinária autônoma \\ RESUMO
}

\begin{abstract}
Avaliaram-se e compararam-se clinicamente os efeitos de colírios de Citrus lemon (CL) na reparação de úlcera corneal superficial. Foram utilizadas 50 coelhas, distribuídas em cinco grupos experimentais de 10 animais cada. Após a indução da úlcera, três grupos foram tratados com colírios de CL, nas concentrações de 1,5\% (GL1,5), 3\% (GL3) e 5\% (GL5). Um quarto grupo foi tratado com Tween 80 a $8 \%$, diluente utilizado na produção dos colírios de CL, e o quinto grupo, controle, recebeu substituto da lágrima. Os grupos foram distribuídos em dois subgrupos de cinco animais; assim, o primeiro (M1) foi avaliado após 24 horas, e o segundo (M5) após cinco dias. Não houve diferença entre os tratamentos quanto aos sinais clínicos secreção, hiperemia conjuntival, quemose e opacidade corneal. A extensão da úlcera corneal diminuiu, de forma significativa, em todos os grupos no M5, com exceção do GL3, o qual apresentou menor mediana quanto à extensão no M1. O colírio de óleo essencial de Citrus lemon pode ser utilizado no tratamento de ceratites ulcerativas superficiais, sem induzir irritação conjuntival, favorecendo a reepitelização corneal.
\end{abstract}

Palavras-chave: coelho, limão-siciliano, ceratite ulcerativa, Rutaceae, óleo essencial

\begin{abstract}
The aim of this study was to clinically evaluate and compare the effects of Citrus lemon (CL) eye drops in the repair of superficial corneal ulcers. Fifty female rabbits were used, constituting five experimental groups with 10 animals each. After ulcer induction, three groups were treated with CL eye drops, at 1.5\% (GL1, 5), 3\% (GL3) and 5\% (GL5) concentrations. Another group was treated with Tween $808 \%$ solvent used in the production of CL eye drops, and the control group received tear substitute. The experimental groups were divided into two subgroups (five animals). The first (M1) was evaluated after 24 hours and the second (M5) after five days. There was no difference between treatments for clinical signs of secretion, conjunctival hyperemia, chemosis and corneal opacity. The extension of corneal ulcer significantly decreased in all groups in M5, the exception was GL3, which had a lower median of extension in the M1. The eye drops made of Citrus lemon essential oil can be used in the treatment of superficial ulcerative keratitis, without inducing conjunctival irritation, favoring corneal reepithelialization.
\end{abstract}

Keywords: rabbit, sicilian lemon, ulcerative keratitis, Rutaceae

\section{INTRODUÇÃO}

As ceratites ulcerativas estão entre as doenças oculares mais comuns, devido à exposição constante da córnea ao meio ambiente (Gilger et

Recebido em 29 de julho de 2011

Aceito em 2 de janeiro de 2012

* Autor para correspondência (corresponding author)

E-mail: valeriasb@fmvz.unesp.br al., 2007). São caracterizadas por lesões erosivas superficiais ou profundas na córnea, com perda de epitélio e exposição do estroma (Gilger et al., 2007). Os sinais mais evidentes nas ceratites ulcerativas são: blefaroespasmo, fotofobia, epífora, edema corneal, infiltração celular, 
secreção ocular e vascularização (Laus, 1998; Galera et al., 2009).

Para o sucesso dos procedimentos terapêuticos, deve-se, primordialmente, realizar a identificação e a eliminação da causa. Entre os principais procedimentos clínicos adotados, encontram-se a terapia antibiótica, os analgésicos, os agentes lubrificantes, a atropina e as drogas antiproteases (Nasisse, 1996; Gilger et al., 2007).

Os óleos essenciais são conhecidos por suas propriedades antissépticas e medicinais de sua fragrância (aromaterapia). São usados na preservação de alimentos e como antimicrobianos, analgésicos, sedativos, anti-inflamatórios, espasmolíticos e agentes anestésicos locais, entre outros (Bakkali et al., 2008). Citrus lemon Burm. f. pertence à família Rutaceae, é popularmente conhecido no Brasil como limão-siciliano e o seu óleo essencial é extraído da casca da fruta (Aloisi et al., 2002; Ceccarelli et al., 2004). Os seus principais componentes são dois monoterpenos: limoneno e $\beta$-pineno, sendo o primeiro o principal constituinte dos óleos essenciais de cítrus (Rozza et al., 2011). O efeito bactericida dos ácidos presentes nos óleos essenciais é diretamente proporcional ao aumento da sua concentração (Tamblyn et al., 1993). Fisher e Phillips (2006) demonstraram a ação inibitória do óleo essencial de Citrus lemon sobre o crescimento in vitro das bactérias Campylobacter jejuni, Escherichia coli, Listeria monocytogenes, Bacillus cereus e Staphylococcus aureus.

Dentre as substâncias naturais encontradas na natureza, os terpenos constituem o principal composto químico com atividades antiulcerogênicas (Lewis e Hanson, 1991). O tratamento de úlceras gástricas de ratos com Citrus lemon promoveu aumento na proliferação celular, na vascularização e de células importantes na resposta às lesões locais, na região da úlcera estomacal, diminuindo o seu tempo de cicatrização (Rozza et al., 2007). Além disso, também foi capaz de evitar a formação da úlcera gástrica, pelo estímulo à produção de muco, efeitos antioxidantes e anti-inflamatórios (Rozza et al., 2011). Moraes et al. (2009) obtiveram resultados semelhantes com o uso de limoneno como protetor da mucosa gástrica.
A ausência de trabalhos sobre o uso de Citrus lemon em oftalmologia e as suas propriedades antiulcerogênicas descritas estimularam $\mathrm{o}$ desenvolvimento deste estudo, com o objetivo de avaliar, por meio de exames clínicooftalmológicos, o processo de reepitelização corneal de úlceras superficiais, induzidas experimentalmente em coelhos, frente ao uso de colírios à base de óleo essencial de Citrus lemon, nas concentrações de $1,5 \%, 3 \%$ e $5 \%$.

\section{MATERIAL E MÉTODOS}

Foram utilizadas 50 coelhas (Oryctolagus cuniculus) pertencentes ao grupo genético Botucatu, com idade variando de 90 a 180 dias e peso entre 2 e $4 \mathrm{~kg}$. Os animais, fornecidos pelo Biotério Central da UNESP, Campus de Botucatu, foram submetidos aos exames clínicos e oftalmológicos de rotina, com auxilio de lâmpada de fenda portátil (Lâmpada de fenda portátil Kowa SL-15®), bem como ao teste de Schirmer (Teste de Schirmer Ophthalmos®), à tonometria (Tonômetro de aplanação Tono Pen® - Med Tronic) e à oftalmoscopia direta (Oftalmoscópio direto Welch Allyn®). Após o procedimento cirúrgico, foram identificados e mantidos em gaiolas individuais, com água potável e ração comercial (Coelhil S - Socyl) ad libitum.

Os procedimentos experimentais seguiram as normas da Association for Research in Vision and Ophthalmology (ARVO) e foram submetidos à Câmara de Ética em Experimentação Animal da Faculdade de Medicina Veterinária e Zootecnia - UNESP Campus de Botucatu. Protocolo número 174/2008 CEEA.

Realizou-se a diluição do polissorbato 80, conhecido como Tween 80 (Tween 80 Labsynth), em solução fisiológica (Solução Fisiológica $\mathrm{NaCl}$ 0,9\% 250mL - Med Flex), na proporção 1:10, obtendo-se a concentração de $8 \%$; em seguida, a solução foi submetida à agitação por 15 minutos em temperatura ambiente para homogeneização. O óleo essencial de Citrus lemon (Citrus lemon - Ferquima) foi diluído, no momento do seu uso, em solução de Tween 80 a $8 \%$, a fim de se obterem as concentrações de $1,5 \%, 3 \%$ e $5 \%$, constituindo, 
deste modo, os respectivos colírios. $\mathrm{O} \mathrm{pH}$ da solução foi ajustado em 7,2, adicionando-se ácido clorídrico (quando necessária a diminuição do $\mathrm{pH}$ ) ou hidróxido de sódio (quando necessário o aumento do $\mathrm{pH}$ ). As soluções foram preparadas em capela de fluxo lamelar unidirecional, estocadas à temperatura de $4^{\circ} \mathrm{C}$, protegidas da luz e utilizadas por até cinco dias. A composição do óleo essencial de Citrus lemon utilizado no experimento apresentou o limoneno como seu principal componente, representando 70,7\%, seguido pelo $\beta$-pineno, com $13,2 \%$, e pelo $\gamma$-terpineno, com $9,2 \%$.

Cinquenta animais foram distribuídos, aleatoriamente, em cinco grupos experimentais. Dois foram designados grupo-controle (GC) e grupo Tween 80 a $8 \%$ (GT), e três designados grupos de colírio à base de Citrus lemon (GL1,5; GL3 e GL5). Cada grupo foi constituído por 10 animais.

No GC, foi instilado colírio substituto da lágrima (Lacrima plus ${ }^{\circledR}$ - Alcon); no GT, os animais foram tratados com colírio de Tween 80 na concentração de $8 \%$; e os do GL1,5, GL3 e GL5 foram tratados com colírio à base de óleo essencial de Citrus lemon, nas concentrações de $1,5 \%, 3 \%$ e $5 \%$, respectivamente.

Os animais foram anestesiados com quetamina (Dopalen ${ }^{\circledR} \quad-$ Vetbrands) $\quad(20 \mathrm{mg} / \mathrm{kg})$, via intramuscular (IM), associada à xilazina (Anasedan ${ }^{\circledR}$ - Vetbrands) $(1 \mathrm{mg} / \mathrm{kg})$ IM e à morfina (Dimorf® - Cristália) $(0,5 \mathrm{mg} / \mathrm{kg}) \mathrm{IM}$. Adicionalmente, foi feita a anestesia tópica ocular por meio de utilização de colírio anestésico (Anestalcon ${ }^{\circledR} \quad-$ Cloridrato do proximetacaína $0,5 \%$ - Alcon).

Os procedimentos operatórios foram realizados com auxílio de microscópio cirúrgico (Microscópio Cirúrgico Karl Kaps, modelo SOM 62 Standarad, Alemanha) após antissepsia utilizando solução de polivinilpirrolidona (Iodopovidona tópico - Rioquimica) a 1:50 e colocação de panos fenestrados oftálmicos estéreis. A fixação mecânica das pálpebras foi feita com blefarostato Barraquer infantil. Para a indução da úlcera corneal, uma haste de algodão foi embebida em n-heptanol e aplicada sobre a córnea a partir do limbo, de forma centrípeta, mantendo o contato do álcool com a córnea durante três minutos. A remoção do epitélio foi realizada com uma haste de algodão seca e, posteriormente, a superfície ocular foi lavada com $60 \mathrm{~mL}$ de solução fisiológica estéril a $0,9 \%$ para a remoção dos debris e do álcool remanescentes (Sampaio et al., 2006). Todos os animais foram submetidos ao procedimento cirúrgico de indução de úlcera de córnea experimental.

No pós-cirúrgico imediato e a cada 12 horas, foi administrado, em todos os animais, o antiinflamatório à base de meloxicam (Movatec ${ }^{\circledR}$ Meloxicam solução injetável - Boehringer Ingelheim) $(0,2 \mathrm{mg} / \mathrm{kg})$, por via subcutânea (SC), além de morfina (Dimorf® - Cristália) $(2 \mathrm{mg} / \mathrm{kg}$ ) $\mathrm{SC}$, durante três dias, visando maximizar o conforto pós-operatório. Os animais foram medicados com os colírios, de acordo com o seu grupo experimental, quatro vezes ao dia, iniciando-se o tratamento logo após a recuperação anestésica. Na região ocular, foram feitas limpezas diárias das pálpebras, quando necessário, com solução salina a 0,9\% (Solução Fisiológica $\mathrm{NaCl}$ 0,9\% 250mL - Med Flex), até o final do período de avaliação de cada animal.

Todos os grupos foram divididos em dois subgrupos constituídos por cinco animais cada, de acordo com o seu período final de avaliação, ou seja, M1, avaliados 24 horas pós-cirurgia (dia 1), e M5, no quinto dia pós-operatório.

Os sinais clínicos oftalmológicos avaliados foram blefaroespasmo, hiperemia conjuntival, quemose, secreção ocular, opacidade corneal, vascularização e pigmentação corneal. Esses foram qualificados e quantificados subjetivamente em: (0) ausente, (1) leve, (2) moderado e (3) grave. Também foi estudada a epitelização da córnea, por meio da realização do teste de fluoresceína (Fluoresceína sódica 1\% colírio - Allergan) e classificação da extensão da úlcera corneal, utilizando-se os escores: (0) ausente, na coloração negativa para fluoresceína; (1) leve, coloração de até $30 \%$ da extensão; (2) moderada, tingimento por fluoresceína entre $30 \mathrm{e}$ $70 \%$ da superfície corneal; e (3) grave, para extensão acima de $70 \%$ da superfície corneal.

Utilizou-se a análise de variância não paramétrica para o modelo de medidas repetidas 
em grupos independentes, com 5\% de significância $(\mathrm{P}<0,05) \quad($ Johnson e Wichern, 2002).

\section{RESULTADOS}

Não houve diferenças significativas entre os grupos em todos os momentos avaliados, bem como entre os momentos, para as variáveis: secreção ocular, hiperemia conjuntival, quemose e opacidade corneal. $\mathrm{Na}$ avaliação da secreção ocular, as medianas dos resultados obtidos variaram de ausente a leve, e, quando presente, esta era mucoide, com exceção de um animal do GL5 e outro do GL1,5, ambos do M5, que demonstraram secreção ocular purulenta.

A hiperemia conjuntival foi observada na maioria dos animais, porém com intensidades diferentes. No primeiro momento de avaliação (M1), os grupos com as menores medianas foram o GC, GL5 e GL3, demonstrando hiperemia leve, enquanto no GL1,5 a mediana foi de intensidade grave. Este grupo também apresentou quemose de intensidade grave no primeiro dia de avaliação, enquanto nos demais grupos observou-se quemose leve ou ausente.

A opacidade corneal foi observada em praticamente todos os animais, variando de leve (maioria dos animais) a grave. Apenas um caso do GL3 não apresentou opacidade no M5.

Quanto ao blefaroespasmo, entre os momentos não houve diferença significativa em todos os grupos, e no M1, todos os grupos comportaramse de maneira similar. Entretanto, no M5 foi verificada maior intensidade desse sinal clínico no GL1,5 quando comparado ao GC; os demais grupos apresentaram valores intermediários e não diferiram do GC e do GL1,5 (Tab. 1).

Tabela 1. Mediana e valores mínimos e máximos da variável blefaroespasmo segundo os grupos e os momentos de avaliação, em dias

\begin{tabular}{lcc}
\hline Grupo & 1 dia (M1) & 5 dias (M5) \\
\hline GC & $0,0(0,0 ; 3,0) \mathrm{a}$ & $0,0(0,0 ; 0,0) \mathrm{a}$ \\
GT & $1,0(0,0 ; 3,0) \mathrm{a}$ & $0,0(0,0 ; 1,0) \mathrm{ab}$ \\
GL5 & $0,0(0,0 ; 2,0) \mathrm{a}$ & $0,0(0,0 ; 3,0) \mathrm{ab}$ \\
GL3 & $0,0(0,0 ; 2,0) \mathrm{a}$ & $0,0(0,0 ; 1,0) \mathrm{ab}$ \\
GL1,5 & $2,0(0,0 ; 3,0) \mathrm{a}$ & $1,0(0,0 ; 3,0) \mathrm{b}$ \\
\hline
\end{tabular}

Letras minúsculas comparam os grupos quando fixado o momento de avaliação. Letras maiúsculas comparam os momentos dentro do mesmo grupo. GC (grupo-controle), GT (grupo Tween), GL5 (grupo Citrus lemon 5\%), GL3 (grupo Citrus lemon 3\%) e GL1,5 (grupo Citrus lemon 1,5\%). Escores: 0-ausente; 1-leve; 2-moderado; 3-grave.

Todos os animais do M1 em GC e GT apresentaram úlceras corneais graves; no GL5 e GL1,5 foram quatro casos de intensidade grave e um moderado, enquanto o GL3 apresentou apenas dois animais com úlceras corneais graves e três moderadas. Após cinco dias, houve redução da gravidade da extensão da úlcera corneal em todos os grupos (Tab. 2).
Não houve diferença significativa, entre os grupos em M1 e M5, quando fixado o momento. Porém, quando comparados os momentos, GC, GT e GL5 apresentaram diminuição da úlcera corneal significativa no M5 em relação ao M1 $(\mathrm{P}<0,01)$, e em relação ao GL1,5 $(\mathrm{P}<0,05)$. No GL3 não houve diferença significativa entre os momentos (Tab. 2).

Tabela 2. Mediana e valores mínimos e máximos da variável úlcera corneal segundo os grupos e os momentos de avaliação, em dias

\begin{tabular}{lcc}
\hline Grupo & 1 dia & 5 dias \\
\hline GC & $3,0(3,0 ; 3,0) \mathrm{A}$ & $1,0(0,0 ; 1,0) \mathrm{B}$ \\
GT & $3,0(3,0 ; 3,0) \mathrm{A}$ & $0,0(0,0 ; 1,0) \mathrm{B}$ \\
GL5 & $3,0(2,0 ; 3,0) \mathrm{A}$ & $1,0(0,0 ; 2,0) \mathrm{B}$ \\
GL3 & $2,0(2,0 ; 3,0) \mathrm{A}$ & $1,0(0,0 ; 3,0) \mathrm{A}$ \\
GL1,5 & $3,0(2,0 ; 3,0) \mathrm{A}$ & $2,0(0,0 ; 2,0) \mathrm{B}$ \\
\hline
\end{tabular}

Letras minúsculas comparam os grupos quando fixado o momento de avaliação. Letras maiúsculas comparam os momentos dentro do mesmo grupo. GC (grupo-controle), GT (grupo Tween), GL5 (grupo Citrus lemon 5\%), GL3 (grupo Citrus lemon 3\%) e GL1,5 (grupo Citrus lemon 1,5\%). Escores: 0-ausente; 1-leve; 2-moderado; 3-grave 


\section{DISCUSSÃO}

A resposta patológica da córnea a qualquer lesão é limitada; assim, muitas afecções podem causar a sua opacidade e consequente perda da visão (Gilger et al., 2007). Os animais domésticos são frequentemente acometidos por afecções corneais, e muitos são os estudos visando à reparação delas com o mínimo possível de sequelas. Este experimento realizou indução de úlcera corneal superficial em coelhos e propôs um novo tratamento à base de um produto natural de distribuição mundial, que apresenta diversas propriedades biológicas.

A utilização dos óleos essenciais no tratamento de doenças já era relatada na época do Egito antigo, no ano de 1480 a.C. (Baser e Buchbauer, 2009), e estende-se até os dias atuais em virtude da procura por medicamentos naturais alternativos para manter a saúde. Apesar do crescente aumento no uso do óleo essencial de Citrus lemon, ainda são poucos os estudos científicos que comprovam as suas propriedades (Yang et al., 2010). O uso do óleo essencial de Citrus lemon desperta o interesse na descoberta de suas propriedades e possíveis aplicações em afecções oculares devido à ausência de relatos, na literatura consultada, considerando-se o seu uso em oftalmologia, além da sua ampla distribuição mundial e no Brasil, e disponibilidade à matéria-prima. Por ser um trabalho inédito no tratamento de ceratites ulcerativas com cítrus, houve a necessidade de se estudarem diferentes concentrações de colírios à base do seu óleo essencial, com o objetivo de se estabelecer a concentração com melhores resultados, proporcionando a base para estudos futuros.

O óleo essencial de Citrus lemon foi diluído em Tween 80 a $8 \%$, que é um produto tensoativo hidrofílico, empregado para obter emulsões do tipo óleo em água. Por ser um produto oleoso, não foi possível a diluição do cítrus em colírio substituto da lágrima, havendo a necessidade de um grupo para controle dos efeitos do Tween sobre a córnea. Optou-se por instilar os colírios quatro vezes ao dia, já que o cítrus possui ação antimicrobiana (Fisher e Phillips, 2006) e Gilger et al. (2007) recomendam a aplicação tópica de antibióticos em úlceras superficiais não complicadas, três a quatro vezes ao dia, apenas para prevenir infecções bacterianas secundárias.
Com a metodologia utilizada, tentou-se reproduzir cirurgicamente úlceras superficiais não complicadas, que, segundo Gilger et al. (2007), demoram de dois a seis dias para cicatrizar; enquanto Gelatt (2003) e Slatter (2005) descrevem a reepitelização corneal ocorrendo dentro de quatro a sete dias. Para avaliar os efeitos iniciais e tardios do Citrus lemon no tratamento dessa doença, estabeleceuse a avaliação dos animais em dois diferentes momentos, sendo o primeiro logo após 24 horas de tratamento e o segundo no período final de reepitelização corneal, após cinco dias de pósoperatório.

$\mathrm{Na}$ avaliação dos sinais clínicos oftalmológicos, que caracterizam as ceratites ulcerativas, não foram observadas diferenças estatísticas entre secreção ocular, hiperemia conjuntival, quemose e opacidade corneal, indicando comportamento similar dos colírios de cítrus e lágrima artificial. Entretanto, ao se compararem as medianas, em que os extremos são descartados, pôde-se notar que, tanto no primeiro momento quanto no segundo, o GL3 obteve escores mais favoráveis, de forma isolada ou junto com outros grupos, enquanto o GL1,5 foi o grupo com pior desempenho na maioria das variáveis analisadas nos dois momentos, o que sugere que a menor concentração de Citrus lemon não apresentou o mesmo comportamento no alívio dos sinais clínicos causados pela ceratite ulcerativa superficial.

Ao se avaliar a quemose, o grupo tratado com óleo essencial de Citrus lemon a 3\% foi o único que apresentou apenas um animal acometido no M1. Embora a quemose tenha sido de intensidade grave, sugere-se variação individual, já que os demais grupos apresentaram de três a quatro animais com quemose de diversas intensidades. $\mathrm{O}$ bom resultado obtido no início do tratamento pelo GL3 demonstra a ausência de irritação conjuntival causada pelo óleo essencial de limão-siciliano a 3\%. Em relação à hiperemia conjuntival, outro parâmetro para se avaliar a possível irritação causada pelo cítrus, os grupos GL3 e GL5 obtiveram medianas semelhantes ao GC no M1, enquanto no M5 o GL3 e GL1,5 apresentaram medianas de escore 0 , já nos demais grupos foram 1, reforçando a ideia de que esse produto natural, quando ajustado o seu $\mathrm{pH}$ para o neutro, pode ser utilizado de forma ocular tópica sem causar irritações. 
Quanto à secreção ocular, no primeiro momento de avaliação, os grupos com melhor mediana foram o GT e o GL3, com acometimento de dois olhos cada, enquanto o GL1,5 apresentou quatro animais com secreção. No período final de avaliação, os melhores resultados foram no controle, com apenas um animal com secreção leve; os grupos GT e GL3 também obtiveram bons resultados com apenas um animal com secreção ocular moderada, e novamente o GL1,5 com três animais com secreção e a pior mediana. O fato de o GT e o GL3 destacarem-se no primeiro período de avaliação e terem obtido resultados parecidos com o do GC no final, assim como a ausência de secreção purulenta nesses grupos, indica um bom controle da ação microbiológica, sem que ocorra irritação da conjuntiva por parte do óleo essencial de Citrus lemon na concentração de 3\%, o que corrobora estudos que demonstraram a ação antimicrobiana do Citrus lemon (Fisher e Phillips, 2006; Bakkali et al., 2008).

O blefaroespasmo é o espasmo tônico do músculo orbicular e avalia a sensibilidade ocular (Galera et al., 2009). Na avaliação desse sinal clínico, no primeiro momento, os grupos que apresentaram menos animais com blefaroespasmo foram o GC, GL5 e GL3, sendo que apenas os dois últimos não apresentaram casos graves. No segundo momento de avaliação (M5), o GC foi significativamente superior ao GL1,5. Os demais grupos não diferiram de forma significativa tanto do GC quanto do GL1,5. Notou-se, portanto, maior sensibilidade ocular nos animais tratados com colírio de Citrus lemon a 1,5\% em relação ao grupo-controle. Entretanto, pôde-se verificar que os demais grupos não diferiram do controle, o que sugere que os colírios de limão-siciliano nas concentrações de 3 e $5 \%$ não foram responsáveis pelo aumento da sensibilidade ocular, assim como o seu diluente (Tween), podendo ser utilizados no tratamento de úlceras corneais.

A extensão da lesão corneal foi outro parâmetro importante na constatação da reepitelização da córnea após os diferentes tratamentos. No primeiro momento de avaliação, não foram observadas diferenças estatísticas entre os tratamentos, mas é interessante ressaltar que o GL3 apresentou três animais com úlcera moderada e apenas dois graves, enquanto nos grupos GC e GT todos os animais tiveram ceratites ulcerativas graves, o que sugere um efeito positivo do colírio de Citrus lemon a $3 \%$ na proliferação epitelial e no recobrimento do estroma, no início da reepitelização corneal. Porém, ao se compararem os momentos, puderam-se observar úlceras de menor extensão no segundo momento, comprovadas na avaliação estatística, nos grupos GC, GT, GL5 e GL1,5; o único grupo que não demonstrou uma diminuição significativa da extensão da lesão no M5 foi o GL3, provavelmente por ter apresentado animais com úlceras menores no primeiro momento de avaliação.

Rozza et al. (2011) trataram úlceras gástricas de ratos com óleo essencial de Citrus lemon e observaram aumento da proliferação epitelial e celularidade da submucosa, diminuindo o tempo de cicatrização da úlcera. $\mathrm{O}$ bom resultado obtido pelo GL3 no início do tratamento, embora não comprovado estatisticamente, pode ser pelo efeito do Citrus lemon estimulando a proliferação celular.

O epitélio apresenta grande capacidade de regeneração, e, consequentemente, úlceras superficiais não complicadas cicatrizam rapidamente (Gilger et al., 2007). Já ceratites ulcerativas profundas, em que há lesão epitelial e estromal, além de maior envolvimento da flora bacteriana, apresentam mecanismos mais complexos de reparação celular (Gilger et al., 2007). Nesses casos, talvez o tratamento com colírio de Citrus lemon destaque suas propriedades, principalmente quanto ao seu efeito no estímulo da proliferação epitelial, aumento da celularidade e vascularização (Rozza et al., 2007), acelerando a cicatrização.

É importante ressaltar que se trata de um produto natural disponível no Brasil, o qual se mostrou bem tolerado na superfície ocular. Estudos posteriores devem ser estimulados, com modificações na metodologia, reduzindo-se o número de ensaios quanto à concentração do colírio e ampliando-se o número de animais, bem como a sua avaliação em úlceras corneais que apresentem processos de reparação mais complexos. 


\section{CONCLUSÕES}

Os sinais clínicos oftalmológicos decorrentes das ceratites ulcerativas superficiais em coelhos são similares nos animais tratados com colírios à base de óleo essencial de Citrus lemon nas diferentes concentrações. O colírio de óleo essencial de Citrus lemon pode ser utilizado no tratamento de ceratites ulcerativas superficiais, sem induzir irritação à superfície ocular, favorecendo a reepitelização corneal.

\section{AGRADECIMENTOS}

À FAPESP (Fundação de Amparo à Pesquisa e Ensino do Estado de São Paulo), pelo apoio financeiro.

\section{REFERÊNCIAS}

ALOISI, A.M.; CECCARELLI, I.; MASI, F.; SCARAMUZZINO, A. Effects of the essential oil from Citrus lemon in male and female rats exposed to a persistent painful stimulation. Behav. Brain Res., v.136, p.127-135, 2002.

BAKKALI, F.; AVERBECK, S.; AVERBECK, D.; IDAOMAR, M. Biological effects of essential oils - A review. Food Chem. Toxicol., v.46, p.446-475, 2008.

BASER, K.H.C.; BUCHBAUER, G. Handbook of Essential Oils: Science, Technology and Applications. Boca Raton: CRC Press, 2009. 991p.

CECCARELLI, I.; LARIVIERE W.R.; FIORENZANI P. et al. Effects of long-term exposure of lemon essential oil odor on behavioral, hormonal and neuronal parameters in male and female rats. Brain Res., v.1001, p.6886, 2004.

FISHER, K.; PHILLIPS, C.A. The effect of lemon, orange and bergamot essential oils and their components on the survival of Campylobacter jejuni, Escherichia coli O157, Listeria monocytogenes, Bacillus cereus and Staphylococcus aureus in vitro and in food systems. J. Appl. Microbiol, v.101, p.1232-1240, 2006.
GALERA, P.D.; LAUS, J.L.; ORIÁ, A.P. Afecções da túnica fibrosa. In: LAUS, J.L. Oftalmologia Clínica e Cirúrgica em Cães $e$ Gatos. 1.ed. São Paulo: Roca, 2009. cap.4, p.6996.

GELATT, K. N. Manual de Oftalmologia Veterinária. Barueri: Manole, 2003. 594p.

GILGER, B.C.; BENTLEY, E.; OLLIVIER, F.J. Diseases and surgery of the canine cornea and sclera. In: GELATT, K.N. Veterinary Ophthalmology. 4.ed. Iowa: Blackwell Publishing, 2007. chap. 15, p.690-752.

JOHNSON R.A.; WICHERN D.W. Applied multivariate statistical analysis. 5.ed. New Jersey: Prentice-Hall, 2002. 767p.

LAUS, J.L. Condiciones corneanas e queratoplastias. In: CONGRESSO DA ASSOCIAÇÃO MUNDIAL DE MEDICINA VETERINÁRIA DE PEQUENOS ANIMAIS, 23., 1998, Buenos Aires. Ophthalmology Presentations. Buenos Aires, 1998.

LEWIS, D.A.; HANSON, P.J. Anti-ulcer drugs of plant origin. Prog. Med. Chem., v.28, p.201$231,1991$.

MORAES, T.M.; KUSHIMA, H.; MOLEIRO, F.C. et al. Effects of limonene and essential oil from Citrus aurantium on gastric mucosa: role of prostaglandins and gastric mucus secretion. Chem. Biol. Interact., v.180, p.499-505, 2009.

NASISSE, M.P. Canine ulcerative keratitis In: GLAZE, M.B. The Compendium Collection: Ophthalmology in Small Animal Practice. 2.ed. New Jersey: Veterinary Learning Systems, 1996. chap. p.45-57.

ROZZA, A.L.; MORAES, T.M.; KUSHIMA, H. et al. Gastroprotective mechanisms of Citrus lemon (Rutaceae) essential oil and its majority compounds limonene and $\beta$-pinene: Involvement of heat-shock protein-70, vasoactive intestinal peptide, glutathione, sulfhydryl compounds, nitric oxide and prostaglandin E2. Chem. Biol. Interact., v.189, p.82-89, 2011. 
ROZZA, A.L.; ORTIZ, M.; HIRUMA-LIMA, C.A.; PELLIZZON, C.H. Healing activity of Citrus lemon (Rutaceae) fruit barks essential oil on gastric ulcer in rats: morphological and ultrastructural studies. In: CONGRESO ITALOLATINOAMERICANO DE ETNOMEDICINASILAE, 16., 2007, La Plata. Anais... La Plata:Cajar. 2007. p.341-342.

SAMPAIO, R.L.; RANZANI, J.J.T.; JÚNIOR, V.R. et al. Aspectos clínicos e imunopatológicos da ceratoplastia com membrana amniótica xenógena fresca e conservada em glicerina. Estudo experimental em coelhos. Arq. Bras. Med. Vet. Zootec., v.58, p.1077-1085, 2006.
SLATTER, D. Fundamentos de Oftalmologia Veterinária. 3.ed. São Paulo: Roca, 2005. 686p.

TAMBLYN, K.C.; CONNER, D.E.; BILGILI, S.F.; HALL, G.S. Utilization of the skin attachment model (SAM) to determine the antibacterial activity of potential carcass treatments. Poult. Sci, v.72, p.278, 1993.

YANG, S.A.; JEON, S.K.; LEE, E.J. et al. Comparative study of the chemical composition and antioxidant activity of six essential oils and their components. Nat. Prod. Res., v.24, p.140$151,2010$. 